of suitable capacity, and the bisulphite as it left the tank to flow into the storage or service reservoir. Assuming that on the large scale the same results can be obtained as in the laboratory, and there appears to be no reason why such should not be the case, the adoption of such a method of water purification may result in an enormous saving in capital expenditure and very greatly reduce the risk of waterborne epidemics.

\section{Clinital aldes:}

\section{MEDICAL, SURGICAL, OBSTETRICAL, AND THERAPEUTICAL.}

\section{HERPES ZOSTER FRONTALIS ASSOCIATED WITH GLAUCOMA.}

By A. A. Bradburne, F.R.C.S. Edin.

THE chief feature which is generally relied upon to distinguish glaucoma from iritis is the size of the pupil. A recently published work says: "In glaucoma there is increased tension. In iritis the tension is usually normal, but for those who cannot rely on their estimation of tension there are other valuable points on which to base the diagnosis ...... it is the pupil which will in most cases give us the necessary clue. In glaucoma the pupil is dilatedoften pear-shaped. In iritis the pupil is contracted." Glaucoma can, however, be associated with a contracted pupil when the iris is fastened down to the lens capsule behind, thus shutting off the posterior from the anterior chamber of the eye. The recognition of such an atypical condition is easy if one be careful to note the plane of the iris which will be either that of the underlying lens, to which it is completely attached, or else ballooned out (iris bombé) by pressure of the aqueous behind it, the edge of the pupil by its attachment to the lens giving the pupil a characteristically cupped appearance.

The interesting feature of this case is the fact that although there was undoubted increase of ocular pressure the pupil was not dilated; such a combination of symptoms is quite compatible with an iritis in which the plus tension is due to congestion and swelling of the iris and increased viscosity of the aqueous fluid. What made the case still simulate iritis was the marked swelling of the upper lid and the accompanying intense conjunctival injection; in fact, a superficial preliminary examination presented a typical picture of iritis, and had not the eye been most carefully scrutinised the instillation of a mydriatic would have seemed urgently necessary. On account of the oedema of the upper lid making recognition of increased intra-ocular tension difficult, this feature, contra-indicating the use of a pupildilating agent, could easily have been overlooked. Had, therefore, a mydriatic been instilled, as symptoms seemed to call for, a most unfortunate result would assuredly have followed. The cultivation of a faculty for observing minutix of detail is the secret of making correct diagnosis in eye affections. Now, not only had Dr. Weldon C. Carter correctly estimated the presence of increased tension, but had further noted that there; was an absence of the rose-red ring of ciliary injection around the corneo-scleral margin which is always present in inflammation of the iris and ciliary body. He had also noted that the cornea was clear and bright and the iris markings were not obscured, and the pupil was fairly mobile. It was plainly evident, then, that a combination of signs was present which were contradictory in character, and for this reason desired my opinion to help to solve the problem.

The patient was a single woman, aged 53 years, the subject of rheumatoid arthritis attacking mainly the ankleand shoulder-joints. Her skin was hot and dry, the tongue was furred, and the left side of the face and head was duskyred and congested. For three days she had been suffering from a most intense pain radiating from the left eye over the forehead, the left side of the nose, and face. As already stated, the upper lid was considerably swollen and in a condition of partial ptosis. The conjunctiva lining the eyelids was congested and to a certain extent the ocular portion as well. Some thin transparent mucus was present as well as profuse lacrymation, and the eye was very sensitive to light and even to the slightest touch. The pupil was four millimetres in diameter, not perfectly circular, and moved under light stimulus. The colour and markings of the iris were unaltered, the cornea reflected brightly, and the media were perfectly clear. The anterior chamber was shallow, and gentle careful palpation revealed increased tension. Some recession of the optic nerve head could be seen, but was not in the condition associated with the later stages of glaucoma. The temperature and pulse were normal. There was another symptom which was out of all proportion to the objective signs, and this was the severity of the pain, its intensity being such as is usually associated with an attack of acutc glaucoma. The clearness of the cornea, the absence of dusky venous engorgement of the ocular conjunctiva, as well as the absence of extreme hardness of the eyeball negatived a diagnosis of acute glaucoma. Against the case being iritis was the mobility of the pupil, the clearness of the texture of the iris, and the absence of ciliary injection. It was evident, then, that the increase of tension was only a secondary manifestation of a cause which had not so far revealed itself. When the patient first consulted Dr. Carter complaining of the severe pain in and around the orbit, he considered the probability of herpes zoster and kept this probability in view until the development of the eye affection led him to weigh the possibility that the cause might arise from the eye itself. 24 hours after my seeing the patient a crop of vesicles developed on the forehead, which at once revealed the true nature of the affection.

During the course of the disease a change came over the condition of the eye which entailed the necessity for a second consultation. This time the eye was found to be free from pain, photophobia, and sensitiveness to touch. The tension was subnormal, the anterior chamber deep, the pupil semi-dilated and immobile, and the texture of the iris was partially obscured. The explanation of these altered appearances was simple. There was evidently a thin viscid but transparent mucoid secretion present in the aqueous which accounted for the loss of transparency of the media and obscured the texture of the iris. The minus tension could be attributed to the defective secretory function of the ciliary body due to the paralysing effect of the affection on the long ciliary nerves. These symptoms indi. cated the urgent necessity of preventing adhesions forming between the iris and the lens capsule which the viscid mucus in the anterior chamber of the eye tended to produce. The use therefore of a mydriatic was obviously required now as much as it was contra-indicated in the early condition and under this treatment the eye rapidly recovered.

The case is considered worthy of record if only on account of the manner in which it indicates the importance of observing the minutest details and correctly gauging their true indications and how it is possible for the so-called classical symptoms at times to become absolutely misleading. Southport.

\section{A CASE OF INTERNAL H EMORRHAGE CONSEQUENT UPON TUBAL GESTATION WITH UNUSUALLY EARLY SYMPTOMS.}

By James Oliver, M.D. EdiN., F.R.S. EdiN.

PHYSICIAN TO THE HOSPITAL FOR WOMEN, SOHO-SQUARE, W

THE patient, aged 27 years and married six years, consulted me on Sept. 30th last. She had had one child but no miscarriage; the child was born five years ago. When I saw her she had had during the previous three weeks a constant hæmorrhagic discharge from the vagina. When this hæmorrhagic discharge made its appearance the patient affirmed that it was the correct time for her being unwell and that she had menstruated as usual four weeks previously. Five weeks before coming under my observation-about two weeks after the last normal menstrual period-she was suddenly seized with severe pain in the right iliac region. This attack lasted altogether about one hour; it was not attended or followed by any hæmorrhagic discharge from the vagina. 14 days after the first attack the patient experienced a second and similar attack of pain and on this occasion the external hæmorrhage made its appearance. During the three weeks that there has been external hæmorrhage there have been three similar attacks of pain; the last attack was on the day preceding her 
visit to me. She complained of no bladder or rectal symptom. With regard to the physical signs, palpation of the abdomen revealed nothing, but the patient kept her abdominal wall rather rigid. The cervix uteri was rather low and was located towards the left wall of the pelvis. The body of the uterus could not be differentiated. In Douglas's pouch and the right quarter of the pelvis was felt a small, firm, and rather convoluted swelling of the consistence of old blood clot.

Operation was performed on Oct. 5th. I opened the abdomen. There was free fluid blood in the general peritoneum which had escaped from the fimbriated extremity of the right tube. The distal end of the right Fallopian tube was the seat of the gestation sac.

Gordon-square, W.C.

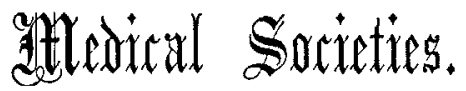

\section{ROYAL SOCIETY OF MEDICINE.}

\section{PATHOLOGICAL SECTION.}

Action of Splenotoxic and Hamolytic Sera.-Idiopathic Dilatation of the Bladder. - Mode of Action of Gastrotoxic Serum and the Healing of Gastrotoxic Ulcers.

A MEETING of this section was held on Nor. 17th, Mr. S. G. SHAтTOCK, the President, being in the chair.

Mr. L. S. DudGeon, Dr. P. N. Panton, and Dr. E. A. Ross communicated a paper on the Action of Splenotoxic and Hæmolytic Sera on the Blood and Tissues. Their experiments were undertaken for the purpose of determining whether it would be possible to produce a splenotoxic serum possessing specific properties, or whether the action of the serum would be on the lymphoid tissue in general, or whether the results obtained were due to the hæmolytic property of the serum. The investigation was further extended to the action of the splenotoxic and hæmolytic sera on the blood and tissue with special reference to the production of fatty degeneration cell necrosis, and the formation of "hæmolymph glands." They immunised three series of rabbits: (1) with splenic extracts; (2) with unwashed blood corpuscles ; and (3) with washed corpuscles obtained from guinea-pigs. The immune sera when injected into guinea-pigs gave results which might be regarded as almost identical, the only difference being that the bæmolytic sera were usually slightly more potent. Another series of rabbits were inoculated with the unwashed blood corpuscles of cats and splenic extracts freed from blood by an elaborate process of washing. The effects resulting from the injection of the splenotoxic and hæmolytic sera were as a rule the death of the animal within 24 hours with small hæmorrhages chiefly into the peritoneum and mesentery, marked swelling and congestion of the spleen, the colour of which was almost jet black, while the remaining viscera were abnormally pallid. In the mesentery dark red glands were found and occasionally similar glands were met with in the groin. The immune sera thus obtained produced changes in the tissues of animals of almost similar character, only they were more pronounced. The fat was of a primrose yellow colour and the viscera and conjunctivæ had a marked "icteroid" tinge. The urine contained a large amount of blood and albumin but no casts and the urine and blood serum were free from bile pigment. The chief microscopical changes consisted of enormous distension of the sinuses of the spleen with red blood corpuscles at the expense of the lymphoid tissue, leaving the Malpighian corpuscles comparatively unaltered and inducing in the endothelial cells a high degree of phagocytosis for erythrocytes and blood pigment. In the affected lymph glands similar histological appcarances to those observed in the spleen, that is to say, so-called hæmolymph glands, were noted. There was widespread necrosis of epithelial cells, particularly in the liver and kidney, and extreme fatty degeneration occurred in the same viscera, but, unlike diphtheritic toxin, spared the heart muscle and diaphragm. When the immune serum was heated or saturated with suitable red cells in vitro the final results obtained were similar to those produced by the untreated serum. With the immune serum obtained from one specimen of animal by inoculating with the tissues of another species and then injected into a third species no abnormal effect was produced.

The Presinent exhibited a Dilated and Hypertrophied Bladder with Double Hydronephrosis from a man who had never suffered from any urinary symptoms, in whom there was no enlargement of any part of the prostate, and whose urethra admitted the passage of a catheter without difficulty. He used the term idiopathic in the way in which it was used in the case of the colon, cesophagus, or stomach, in which similar dilatation and hypertrophy occurred; and of these conditions he gave different tentative explanations. In the case of the pelvic colon the dilatation usually commenced shortly after birth. It was a sionificant fact that in the case of the bladder dilatation without recognisable cause had also been observed in infancy and in the newly born child, one excellent example of the latter being in the Museum of the Royal College of Surgeons of England. The dilatation might be clue to incoördination between the contraction of the detrusor and the dilatation of the sphincter; and there was the theoretical possibility, also, of a hypoæsthetic state of the mucosa whereby the reflex of micturition would not arise until the viscus had reached what in normal circumstances would be an abnormal degree of fulness. Experiments made by Dr. T. G. Brodie and himself showed that in the cat, if the vesical mucosa was anæsthetised by means of cocaine, on the bladder being filled with warm salt solution micturition was abolished, the organ becoming markedly distended. This result indicated that the reflex of micturition was initiated by the tension of the vesical mucosa-i.e., the contraction of the detrusor and the associated dilatation of the sphincter. Whether anæsthesia or hypoæsthesia of mucous membranes occurred as a hysterical phenomenon was a subject that would repay investigation.

Dr. Charles Bolton read a paper on the Mode of Action of Gastrotoxic Serum and the Healing of Gastrotoxic Ulcers. He said that the gastrotoxic serum referred to was prepared by immunising the rabbit with guinea-pig's gastric cells. The action of the serum was manifested in two directions: (1) by the production of general symptoms of intoxication; and (2) by the formation of patches of necrosis in the mucous membrane of the stomach which developed into ulcers. It was proved that the serum acted directly upon the gastric cells and not primarily upon the capillary wall leading to hæmorrhage, because if the gastric juice were neutralised with an alkali at the time that the serum was injected no lesions resulted. Neutralisation of the gastric juice would, of course, not prevent a hæmorrhage occurring. The actual necrosis of the mucous membrane was produced by the gastric juice, because no microscopic change could be seen in the cells when the gastric juice was put out of action. It appeared, therefore, that some pathological change was produced in the cells whereby they were rendered susceptible to digestion by the gastric juice. That pathological change was probably a devitalisation of the cell and not the removal of any specific resisting power possessed by the cells, because other poisons, hepatotoxin, enterotoxin, and hæmolysin, were able to produce an action on the gastric cells of precisely the same nature only to a much less extent. Those two observations, the initiation of self-digestion resulting from the circulation of a poison in the blood and the non-specificity of the poison, were considered of great importance because they raised the question whether there might not be many endogenous and also exogenous poisons (bacterial or otherwise) which by their action on the gastric cells could bring about self-digestion. It was shown that certain protoplasmic poisons in solutions, which were of themselves inert, were able to increase the lesions produced by gastrotoxin if they were introduced into the stomach when the latter was injected into the animal. Such solutions were hydrochloric acid above 0.3 per cent., sulphuric acid above 0.5 , acetic acid above 0.5 , and lactic acid above 2 per cent. It was therefore considered probable that hyperacidity of the gastric juice or the taking of inert solutions of certain substances by the mouth (e.g., vinegar) could in the presence of a devitalising agent in the blood bring about selfdigestion. The gastric lesions produced by hepatotoxin, enterotoxin, and hæmolysin were shown to be increased by the acids also. It was considered that no cytotoxin was specific, each acting especially upon the cells against which 